This item was submitted to Loughborough's Research Repository by the author.

Items in Figshare are protected by copyright, with all rights reserved, unless otherwise indicated.

\title{
Police officer and civilian staff receptivity to research and evidence-based policing in the UK: providing a contextual understanding through qualitative interviews
}

\section{PLEASE CITE THE PUBLISHED VERSION}

http://dx.doi.org/10.1093/police/paw036

\section{PUBLISHER}

Oxford University Press (OUP) / @ The Author.

\section{VERSION}

AM (Accepted Manuscript)

\section{PUBLISHER STATEMENT}

This work is made available according to the conditions of the Creative Commons Attribution-NonCommercialNoDerivatives 4.0 International (CC BY-NC-ND 4.0) licence. Full details of this licence are available at: https://creativecommons.org/licenses/by-nc-nd/4.0/

\section{LICENCE}

CC BY-NC-ND 4.0

\section{REPOSITORY RECORD}

Lumsden, Karen. 2019. "Police Officer and Civilian Staff Receptivity to Research and Evidence-based Policing in the UK: Providing a Contextual Understanding Through Qualitative Interviews". figshare.

https://hdl.handle.net/2134/22355. 
Police Officer and Civilian Staff Receptivity to Research and Evidence-Based Policing in England: Providing a Contextual Understanding through Qualitative Interviews

\title{
Dr Karen Lumsden
}

\begin{abstract}
This paper provides a contextual understanding of police officer and civilian staff receptivity to research and evidence-based policing (EBP) in England through presentation of findings from qualitative interviews. It focuses on: 1) how officers defined the concept of EBP; 2) the context driving these definitions (including political pressures, professionalisation and the rise of police-academic collaborations); 3) what research means to police officers in terms of 'hierarchies' and a 'ladder of evidence' and 4) how success and 'what works' is measured (including academic versus practitioner definitions). It is argued that future studies of police officer and civilian staff receptivity to research and EBP are crucial as receptivity influences the application of research and willingness to incorporate an evidence-base into policing practice. Data is presented from 15 semi-structured interviews with police officers and civilian staff from police forces in England.
\end{abstract}

\section{Keywords}

academia, civilian staff, evidence-base, knowledge, receptivity, research, policing 


\section{Introduction}

This paper focuses on police officer and staff receptivity to research and evidencebased policing (henceforth abbreviated to EBP) in England. EBP is 'a law enforcement perspective and philosophy that implicates the use of research, evaluation, analysis, and scientific processes in law enforcement decision making' (Lum and Koper, 2015: 1). It also focuses on 'which practices and strategies accomplish police missions most cost-effectively' (Sherman, 2013: 377). There is now widespread recognition from police forces in the UK of the benefits that can be gleaned from adopting an evidence-based approach to policing and crime and justice issues. There has been greater emphasis from the Home Office on promoting and funding police-academic partnerships, aiming to build a 'what works' network to inform policing practices. This is reflected in the creation of the College of Policing in 2012, a professional policing body which has a 'mandate to set standards in professional development'. This includes codes of practice and regulations which ensure consistency across the 43 forces in England and Wales (College of Policing, 2015). It promotes an evidence-based approach, for instance via the What Works Centre for Crime Reduction (WWCCR). ${ }^{1}$ Recent years have also seen a proliferation of regional police-academic partnerships across the UK (i.e. the Scottish Institute for Policing Research (SIPR), the Universities Police Science Institute (UPSI), the N8 Policing Research Partnership, the East Midlands Policing Academic collaboration (EMPAC), and the Society for Evidence Based Policing (SEBP)).

Despite the increasing emphasis on EBP and 'what works' in policing in the UK, there has to date been scarce research or insight into police officer and staff receptivity to research and EBP. This includes how it might be understood or utilised 
in various guises by officers and management, and also by officers at various ranks in the organisation. Emerging studies focusing on officers' receptivity to empirical research and EBP have mainly involved quantitative surveys (see Lum et al. 2012; Hunter et al. 2015; Palmer, 2011; Rojek, Alpert and Smith, 2012; Steinheider et al. 2012; Telep, 2016; Telep and Lum, 2012; Telep and Winegar, 2015). This paper provides a contextual element to this growing body of work by presenting qualitative interview data on officer and staff receptivity to research and EBP in England.

It presents findings from 15 semi-structured interviews with police officers and staff from forces in England. The discussion focuses on: 1) how officers defined the concept of EBP; 2) the context driving these definitions (including political pressures, professionalisation and the rise of police-academic collaborations); 3) their discussions of what research means in terms of 'hierarchies' and a 'ladder of evidence' and 4) how success and 'what works' is measured (including academic versus practitioner definitions). The paper concludes by highlighting that future studies of police officer receptivity to research and EBP are crucial as receptivity influences the application of research and willingness to incorporate an evidence-base into policing practice.

\section{Evidence-based policing (EBP)}

The evidence-based practice movement gained momentum in the UK from the 1990s onwards. It originated in the area of medicine (Cochrane, 1972) but also spread to education, management and social care. The central premise of the evidence-based practice movement is to lay down principles which are based on evidence for how best to 'reinforce guidance or methods in practice' (Avby et al. 2014: 1367). 
Evidence-based practice is largely positivistic and focuses on scientific evidence that will produce ‘universal truths’ (Petersen and Olsson, 2015: 1582). This also entails a focus on research for/with the user, experimentation, intelligence-led policing approaches, and prevention and deterrence (Heaton and Tong, 2016). EBP consists of an increasing emphasis on the 'users' or 'consumers' of research (Sherman, 2003: 6). In this sense, EBP acts as a 'motor' - working as an “"engine” for change and improvement' in the realm of policing (Innes, 2010: 128). Notable examples of EBP in the US include research on restrictions of police shootings (Fyfe, 1982) and the use of 'hot-spots' in order to target US police resources to particular areas suffering from small-scale crime (Sherman et al. 1989; Weisburd and Lum, 2005; Police Executive Research Forum, 2008).

EBP primarily emerged in the work of Sherman and others (see Sherman, 1998; 2003; 2013; Sherman et al. 1997) and involves the use of scientific or experimental methods, hypothesis testing of empirical findings, and evaluating 'what works' most cost effectively. Heaton and Tong (2016: 61) argue that: 'Ideally, the effectiveness of a policing intervention would be measured, and an assessment made of whether its costs would justify implementation against a standard; for example, reduction in crimes per cost unit'. According to Sherman (2013) the adoption of the three principles of 'targeting', 'testing' and 'tracking' by police forces have given rise to EBP:

1. Targeting: 'Police should conduct and apply good research to target scarce resources on predictable concentrations of harm from crime and disorder.' 
2. Testing: 'Once police choose their high-priority targets, they should review or conduct tests of police methods to help choose what works best to reduce harm.'

3. Tracking: 'Once police agencies use research to target their tested practices, they should generate and use internal evidence to track the daily delivery and effects of those practices, including public perceptions of police legitimacy.'

(Sherman, 2013: 383)

'Robust' or 'good' evidence is assessed on a five-point scale, based on neo-positivist quality assurance frameworks such as the 'Maryland Scale of Scientific Methods' (Sherman, 2013). The Maryland Scale was originally designed to rate the internal validity of individual studies and on its own it was not an assessment of whether things worked or not, but rather whether the evidence was believable based on study methodology. Lum et al. (2011; see also Lum et al. 2012) have developed the 'Evidence-Based Policing Matrix’ as a means of translating research into policing practice. The aim of the interactive Matrix is to assist in making 'the large body of police crime prevention research more usable and accessible' for police in the USA (Lum et al. 2012: 82). This includes all evaluations of interventions which are at least ‘moderately rigorous' being 'individually mapped onto a three-dimensional visualization intended to reveal generalizations across the body of research in order to assist police in developing crime prevention strategies that are evidence-based' (Lum et al. 2012: 82). Building on Sherman's discussion of EBP, Lum and Koper (2015: 5) further argue that we should take note of three distinctions highlighting the difficulty in EBPs fulfilment: 
1. EBP is a 'decision-making perspective, not a panacea.'

2. It is 'grounded in the idea that policies and practices should be supported by research evidence and analytics, not blindly determined by them.'

3. That research is 'not ignored and that it at least becomes a part of the conversation on what to do about reducing crime, increasing legitimacy, or addressing internal problems.'

\section{Criticisms of the evidence-based movement}

Critics of EBP such as Tilley (2009: 143) have pointed out how it risks 'stifling heterodox alternative methodologies rooted in critiques of the RCT'. A controversial issue in EBP is the 'focus on evidence of effectiveness' with the aforementioned 'gold-standard' of randomised control trials (RCTs) and systematic reviews privileging quantitative methods at the expense of qualitative and/or observational approaches (Pearson, 2010: 489). Veltri et al. (2014) argue that the potential of qualitative research to help decision and policy-making remains largely unexplored. As Fyfe and Wilson (2012: 308) note, in order to effectively inform policing there is a requirement 'to engage with the full spectrum of knowledge requirements and embrace a degree of eclecticism in relation to theoretical frameworks, methodological approaches and types of empirical data'.

Bullock and Tilley (2009) also draw attention to various barriers impacting on the implementation of evidence. These include difficulties in discerning what counts as 'evidence' of effective practice, the availability of evidence, and organisational constraints (such as ideological battles and conflicting interests). Moreover, research in the interest of consumers can be argued to ignore the power dynamics at play 
between (and within) police organisations, government and the public(s) they serve (Hope, 2009). Thatcher (2001: 391) argues that police face a 'broader range and a more ambiguous mix of values' than an instrumental incarnation of evidence-based policing is able to address.

A better understanding of officer receptivity can help to inform academics and practitioners about how best to implement the results of research and evaluations (Lum et al. 2012). However scarce qualitative research has been conducted into police officer understandings of EBP or their utilisation of research evidence, although a growing literature on this can be found in contexts such as social care (see Gray et al. 2015; Pope et al. 2011). Quantitative studies of receptivity to research in US police forces includes a survey of police chiefs and sheriffs in Oregon, which shows that officers are generally receptive to the idea of EBP, but that there are gaps in knowledge and also in use of research evidence (Telep and Winegar, 2015; see also Rojek et al. 2012). Telep and Lum (2012; see also Lum et al. 2012) surveyed officers in three police agencies (the Sacramento, California Police Department (SPD) the Richmond, Virginia Police Department (RPD) and the Roanoke County, Virginia Police Department (RCPD)) to highlight the importance of officer receptivity for organisations to move forward with EBP (Telep, 2016). Lum et al. (2012: 71-72) argue that while the concepts of 'evidence-based' or 'research-based' policing have become common terminology in academia, the term EBP is 'not as well known in the world of practitioners'. Steinheider et al. (2012) surveyed academics and police practitioners to determine their philosophical viewpoints and perceptions of research. They highlight how each values different qualities in a research partnership. In the UK, Hunter et al. (2015) surveyed officers at Inspector level and above (including 
civilian level equivalents) to explore the role of research evidence, their experience of research and the barriers and opportunities encountered. Palmer (2011) found that the majority of police officers in the UK were not involved in evidence-based practices or experimental methods. His respondents also saw education as having little relevance to operational policing. Focusing on frontline officers from four US municipal forces, Telep (2016: 1) further notes that officer awareness of EBP and willingness to work with researchers are influenced by 'education and prior research exposure’.

These studies all indicate that although officers recognise the value of research, dayto-day decision-making tends to be guided more by experience than by scientific evidence (Telep and Winegar, 2015). Koehle et al. (2010: 20) further suggest that police officers might be more receptive to qualitative research than quantitative research, due to 'the nature of qualitative findings - in the words of real people, in response to questions familiar in police work'. This paper contributes to this growing body of literature by providing a contextual understanding of receptivity via qualitative interviews with officers and staff.

Reflections on police-academic partnerships highlight the benefits to be had from participatory action approaches (Fleming, 2012; Wood et al. 2008) in order to overcome the 'dialogue of the deaf' highlighted by Bradley and Nixon (2009). Henry and Mackenzie (2012) write about their experience of conducting knowledge transfer with police in Scotland. This includes the benefits of conceptualising police-academic relationships as ‘communities of practice'. Goode and Lumsden (2016) also highlight their experiences of police-academic partnerships, highlighting the shift from conducting research 'on' police to conducting research 'with' police. They note the 
risks presented to both sides from the 'McDonaldization’ of these partnerships, which includes the influence of public management principles on the research process.

\section{Methods}

The discussion which follows is based on 15 semi-structured interviews conducted during a one-year funded Enterprise Project Grant that focused on developing partnerships and conducting knowledge transfer with police forces in England. This involved a Senior Research Associate spending seven months seconded to one particular police force in the Midlands of England, while conducting networking and other collaborative activities across two additional regional police forces which covered both urban and rural areas. We also liaised with stakeholders including victims’ support organisations, Magistrates’ Courts staff, the College of Policing, and academics across the region engaged in policing research.

Interviews were conducted with individuals who either had key in-force roles in relation to the utilisation of research evidence or who had experience of undertaking research and/or collaborating professionally with academics. Interviewees were recruited with the assistance of a gatekeeper (Chief Inspector) who provided a list of police officers fitting the above criteria. The Senior Research Associate had a 'hot desk' at three different police stations which also resulted in other officers and staff volunteering to participate. The interviews constitute a purposive sample as they were selected to represent a mixture of roles, including officers with operational (Sergeant) and managerial (Inspectors and Chief Inspectors) responsibilities, and staff with policy-related and analytical responsibilities. They were selected purposively in relation to having experience of conducting research (e.g. in-force; on secondment to 
the College of Policing; as part of an external formal qualification; as part of their official responsibilities; in collaboration with academics/other partners). An interview guide was developed and interviews (each lasting approximately one-hour in duration) were recorded and transcribed.

We asked the following questions: 1) How did those we were collaborating with define and conceptualise 'research' and particularly 'evidence-based research’? 2) How did they discuss and make use of evidence-based research in relation to working theories? 3) What was the current role of research in informing policing policy and practice? 4) What contributions did they believe academics could make to policing? 5) What barriers did they envisage both police and academics encountering in building collaborations? 6) What were the most effective ways to pursue such collaborations and overcome potential barriers?

Data was analysed using thematic analysis which allowed us to identify and analyse key themes and patterns emerging from the transcripts (Braun and Clarke, 2006), and to take account of unanticipated topics and themes emerging from the data. The identities of the police forces, police officers and staff have been fully anonymised, as has any descriptive information that might result in identification of the police forces or participants.

\section{Police officer and staff receptivity to research and EBP}

Definitions of EBP

There was often a hint of cynicism in relation to the concept of EBP, with officers defining it as the latest trend or 'buzzword': 
It's the new buzzword... I don't know whether evidence-based policing has reached (my force) as a term... If you went out there and asked somebody, I don't think they'd have a clue what you're talking about. (Interviewee 5, Temporary Inspector)

It was acknowledged by a member of staff that the term is 'widely used' but also that its spread within and across forces is still 'patchy at best':

The terminology is widely used. Whether it's widely understood or widely implemented is another matter... There's a specific module on evidence-based policing... It goes into the more empirical approach... one of the officers came back and he was really impressed... but he said 'I know I'm not going to be able to do any of that here'. (Interviewee 1, police staff)

This officer likens EBP to research which involves 'theory-testing' and the need to place science and evidence behind decision-making. It is viewed as saving money and addressing demand. They also recognise the links to the Maryland Scale (discussed in detail below):

It is a way of saying, 'Ok, here’s a hypothesis, here's a theory, let's try that, and actually let's put some science behind it', so in the future if somebody has a similar problem, they can look at it and go 'Actually, on the Maryland Scale'...you can say 'that looks like a good piece of work... perhaps we don’t need to do that bit or that bit, we can just do some marketing and that will cost 
us a thousand pounds instead of twenty thousand pounds'. (Interviewee 7, Temporary Chief Inspector)

The context driving definitions of EBP

The context driving definitions of EBP was explicitly related to austerity post 2008 recession and as part of the Conservative government reforms to police budgets. According to an Acting Chief Inspector:

We’ve got significant change - have had since 2010 with the Comprehensive Spending Review - massive change in funding models across policing having to do so much more with so much less. And a lot of it's anecdotal 'Oh, this is what we think we need to do' and 43 forces all thinking they're going to do it their way. And then we've got the Police Crime Commissioners $(\mathrm{PCCs})^{2} \ldots$ Quite often the culture is that we don't want to change anything. So we need to have a big stick waved at us. (Interviewee 11, Temporary Chief Inspector)

For this officer EBP was also seen as a potential driver for change, by 'waving a big stick' at forces in order to improve in relation to demand, rather than just addressing the need to save money and police efficiently.

This officer noted that research was now on the agenda because of the increasing focus on 'professionalising' the police: 
The Home Office have given the College of Policing a huge amount of money. So they've got to have results. If the College of Policing have got to have results that are based on professionalising the service, then they need the help of academics and police to work together... (Interviewee 10, Temporary Chief Inspector)

Therefore academics as 'experts' would be well placed to work in collaboration with police in order to instigate evidence-based change in line with the College of Policing professionalisation agenda. The professionalisation of the police is a contested and on-going process with with organisational, public and government debates and discourses focusing on the negotiation, development and/or introduction of a range of factors including policing as a 'body of knowledge', training and education, how best to serve the public, the extent of autonomy, professional standards, code of behavior and ethics, standards of practice and professional mobility (Rohl, 1990). In this sense, an evidence-based approach can help to form a 'body of knowledge' on best practice.

The importance of partnering up with universities was also highlighted by a member of staff when asked what the idea of EBP meant to them. External research was viewed as beneficial and sitting alongside the 'quick win' in-house research conducted:

I think from an evidence-base, when you can do high-level things, it's great to get universities involved [because] then you can get other forces involved and it's good to collaborate. The internal stuff which is quick turn-around is great as well. (Interviewee 9, staff) 
The notion of 'rubbing shoulders' with academia was also explicitly highlighted by a police officer to be a positive step forward for their force:

I also work separately with the universities looking at individual ways of professional development, if you like, and this is the bit that's growing. I call it the 'rubbing shoulders effect' where the police and academics, the police and students, will rub shoulders together more and more and more until it's business-as-usual and it's not bizarre to have a student in the police station helping somebody with something. (Interviewee 10, Temporary Chief Inspector)

What does 'research' mean? 'ladders' and 'hot-spots'

Police officers also referred to EBP as consisting of a 'hierarchy' or 'ladder' of evidence, demonstrating awareness of the College of Policing's adoption of the 'Maryland Scale' for assessing research:

It usually involves a ladder of some kind... This is a study which doesn't really have much academic robustness... and then at the top you've got this kind of sampling... which is very, very robust... and... that is evidence-based policing, and that's what we should do. (Interviewee 6, Inspector)

The 'gold standard' and 'robustness' were highlighted by another Inspector, who also demonstrates the focus on neo-positivist methods at 'one end' of the scale and with qualitative research at the 'other end'. Here we see implications for the potential 
legitimation of various forms of research and its impact on practice, although the officer points out that they view both quantitative and qualitative evidence as equally important:

You're talking about the gold standard of research and the randomised control trials at one end... and then your qualitative side of stuff (of what people think, feel, and their emotions)... on the other side. For me, they're both equally important. You can’t do one without the other... What we’ve got to do as a force is invest a little bit more in on the qualitative side of stuff and then we can get to a point where it's embedded, where we can use mixed methods. (Interviewee 8, Inspector)

An acting Chief Inspector provided an example of the use of 'hot-spots' as EBP and allowing for more accurate targeting of police resources, including the potential for replication. However he also highlights the issue of training of various ranks in terms of EBP, and operationally the need for management of officers on the ground:

So what is a hot-spot? It needs to be hot, not lukewarm and... you spend $\mathrm{x}$ number of minutes in that hot-spot and then you move on... Getting people to understand that, at my level, or higher level... this means we can allocate less resources to tackle that. But they need managing because what they found with the tests that they've done - you can say to an officer 'You need to be in that' (like the Met and bus stops) - 'at that bus-stop, for this amount of time', and when you start checking you find they either didn’t go or were there for a longer time or weren't there long enough. You have to put some resource into 
actually managing it. But then you can replicate that across the country. (Interviewee 7, Temporary Chief Inspector)

Measuring success: what type of research 'works'?

A variety of responses were encountered as to how success is measured and 'which' forms of research would 'work' in particular contexts. This included awareness from most interviewees as to the value of both quantitative and qualitative methods. For instance, this Inspector highlighted a need to focus more on qualitative research which would provide insight into people’s experiences:

We focus on the quantitative side of stuff and the number crunching and surveys. We don't tend to focus on the narrative and the rich source of data that we can get from talking to people and finding out people's experiences and perceptions. And for me that's just as valuable. (Interviewee 8, Inspector)

Another officer highlighted the need for research on community engagement and the difficulty that they encounter in demonstrating effective engagement:

We do look at statistics but that's why engagement is really interesting, because you can't measure that but it's clear how people feel is, for me, more important and massive community feedback about how unsafe they are and 'All this crime!' And there’s not... but that's the feeling, that's the perception. But how do you measure that? And if the community feels good? We had a community meeting and I came out and it's like, 'oh, brilliant, we feel a lot better'. And that's like 'brilliant!' But then you think, well, where is that, for 
me to say to anybody (in the organisation): 'The community feels better now?' (Interviewee 5, Temporary Inspector)

This officer is drawing attention to social variables and phenomena, which cannot be measured in a positivist sense. They highlight the need for researchers and police to 'engage with the full spectrum of knowledge requirements' and methods (Fyfe and Wilson, 2012: 308, Tilley, 2009; Lum and Koper, 2015). The requirement to focus on more than quantitative research and a performance-focused mindset was highlighted by this member of staff:

We're hung up on figures and a lot of people will say, 'We've had a 500 per cent increase!' and it's results, results, results. If you've done an operation, we want to see that crime went down the following week [because] it's had an effect. And we need to look longer term at actually what does work - and that's not just your quantitative analysis. (Interviewee 4, staff)

Another member of staff alluded to the 'performance culture', viewing it as a potential barrier to the implementation of research evidence:

The focus on a performance culture and the nature of policing doesn't lend itself to evidence-based practice... When I first started... somebody said, 'the thing to remember about officers and staff is that officers are brilliant in a crisis because that's what they're trained to do. Staff are better at planning. But it's like, never the twain shall meet.' The bit that [officers] enjoy, the 
blues and twos, the exciting stuff - they just like to turn up and just deal with it. (Interviewee 1, staff)

Therefore they also draw attention to the tension between 'practitioner theories' and various forms of 'expert' knowledge, a point which is outside the purview of this paper in terms of full exploration, but which requires greater consideration in future studies in order to inform means of transferring and translating research evidence into policing practice (Tilley, 2015).

\section{Discussion and conclusions}

This paper presented data on police officer and staff receptivity to research and EBP. It highlighted the ways in which EBP is viewed as part of performance culture and as related to the political pressures which police forces face from external agents such as the Home Office and Police Crime Commissioners (PCCs). It also highlighted various organisational and cultural barriers to engagement in, or support for EBP and its implementation (Bullock and Tilley, 2009; Lumsden and Goode, 2016), and that for EBP to succeed requires buy-in from senior officers. Equally, it notes that officer and staff awareness of EBP is currently viewed by officers as 'patchy' across police forces, highlighting a specific gap in knowledge of EBP at frontline and operational levels.

Nonetheless, for the officers and civilian staff interviewed there was clear enthusiasm and support for EBP, and an awareness of the benefits presented by collaborating with academics and ending the 'dialogue of the deaf' (Bradley and Nixon, 2009) and utilising expert research knowledge (alongside in-house research) to address issues of 
demand, cost, effectiveness, and in order to improve the support provided to victims of crime, and engagement with communities.

The paper also focused on the tensions inherent in the definitions of what constitutes EBP in terms of research, and what would be 'of use' to police in various contexts. Greater discussion would be welcomed regarding how practitioners - in this case officers and staff of different ranks and roles - are utilising evidence in various contexts, what they feel this evidence should deliver, and the barriers encountered in its implementation into practice. As Lum et al. (2012: 81) found in their study of officer receptivity, there is evidence that although decision-makers are willing to change the status quo with new ideas, this is only the case it these ideas do 'not go against their personal beliefs or daily routines’.

EBP as employed by the College of Policing in England and Wales consists of a 'hierarchy of evidence' which risks creating a dominant discourse that ignores certain forms of research and knowledge (i.e. qualitative) which police officers and staff may require and which they themselves indicate above as being of use (for example providing greater insight into community engagement). Relying on randomised control trials for instance risks the exclusion of other methods such as observational studies, mixed method research designs, cross-sectional surveys, systematic interviews, social network analysis, and simulations. The current incarnation of EBP as promoted to police officers risks discounting aspects of social scientific research which some officers and staff might find useful in practice. There was also a lack of explicit recognition from officers that what they required, and thus might request from those academics they collaborate with, could potentially fall outside of the 'gold 
standard'. Qualitative research has now been incorporated in medical research to an extent (for example in the Campbell and Cochrane Collaborations) and thus EBP could potentially learn from the inclusion of various methodologies in other contexts (Lumsden and Goode, 2016).

It is important to note that this study involved a small sample of officers who are already tasked with work related to research utilization. Therefore it is important that future work looks at a broader cross section of officers and staff working in a variety of assignments and contexts. Finally, as well as greater understanding of how police officers and staff view EBP and research evidence, there is also a need for research into the views of policing scholars and academics - from across a range of disciplines and utilising a variety of methodologies, in order to further shed light on the barriers and drivers to working in partnership to form an evidence-base for policing.

\section{References}

Avby, G., Nilsen, P. and Dahlgren, M. A. (2014). 'Ways of Understanding EvidenceBased Practice in Social Work: A Qualitative Study.' British Journal of Social Work, 44: 1366-1383.

Bradley, D. and Nixon, C. (2009). 'Ending the "Dialogue of the Deaf”: Evidence and Policing Policies and Practices. An Australian Case Study.' Police Practice and Research, 10(5-6): 423-435.

Braun, V. and Clarke, C. (2006). 'Using Thematic Analysis in Psychology.' Qualitative Research in Psychology, 3(2): 77-101.

Bullock, K. and Tilley, N. (2009). 'Evidence-Based Policing and Crime Reduction.' Policing: A Journal of Policy and Practice, 3(4): 381-387. 
Cochrane, A. (1972). Effectiveness and Efficiency. London: Nuffield Provincial Hospitals Trust.

College of Policing. (2015). 'About Us'. URL (accessed 15 May 2016): http://www.college.police.uk/About/Pages/default.aspx

Fleming, J. (2012). 'Changing the Way We Do Business: Reflecting on Collaborative Practice.’ Police Practice and Research, 13(4): 375-388.

Fyfe, J. J. (1982). 'Blind Justice: Police Shootings in Memphis.’ Journal of Criminal Law and Criminology, 73(2): 707-722.

Fyfe, N. R. and Wilson, P. (2012). 'Knowledge Exchange and Police Practice: Broadening and Deepening the Debate Around Researcher-Practitioner Collaborations.’ Police Practice and Research, 13(4): 306-314.

Goode, J. and Lumsden, K. (2016). 'The McDonaldisation of Police-Academic Partnerships: Organisational and Cultural Barriers Encountered in Moving from Research on Police to Research with Police.' Policing and Society, iFirst: DOI 10.1080/10439463.2016.1147039.

Gray, M., Joy, E., Plath, D. and Webb, S. A. (2015). 'What Supports and Impedes Evidence-Based Practice Implementation? A Survey of Australian Social Workers.' British Journal of Social Work, 45: 667-684.

Heaton, R. and Tong, S. (2016). 'Evidence-based Policing: From Effectiveness to Cost-Effectiveness.' Policing: A Journal of Policy and Practice, 10(1): 60-70.

Henry, A. and McKenzie, S. (2012). 'Brokering Communities of Practice: A Model of Knowledge Exchange and Academic-Practitioner Collaboration Developed in the Context of Community Policing.' Police Practice and Research, 13(4): 315-328.

Hope, T. (2009). 'The Illusion of Control: A Response to Professor Sherman.' Criminology \& Criminal Justice, 9(2): 125-134. 
Hunter, G., Wigzell, A., May, T. and McSweeney, T. (2015). An Evaluation of the 'What Works Centre for Crime Reduction': Year 1. London: Birkbeck University of London.

Innes, M. (2010). ‘A “Mirror” and a "Motor”: Researching and Reforming Policing in An Age of Austerity.' Policing: A Journal of Policy and Practice, 4(2): 127-134.

Koehle, G., Six, T. and Hanrahan, K. (2010). 'Citizen Concerns and Approval of Police Performance.’ Professional Issues in Criminal Justice, 5: 9-24.

Lum, C. and Koper, C. S. (2015). ‘Evidence-Based Policing.’ In Dunham, R. G. and Alpert, G. P. (eds), Critical Issues in Policing, Seventh Edition. Long Gove, IL: Waveland Press.

Lum, C., Koper, C.S. and Telep, C.W. (2011). 'The Evidence-Based Policing Matrix.’ Journal of Experimental Criminology, 7(1): 3-26.

Lum, C., Telep, C. W., Koper, C. S. and Grieco, J. (2012). 'Receptivity to Research in Policing.' Justice Research and Policy, 14(1): 61-95.

Lumsden, K. and Goode, J. (2016). 'Policing Research and the Rise of the "EvidenceBase”: Police Officer and Staff Understandings of Research, its Implementation and "What Works.”' Sociology, iFirst.

Palmer, I. (2011). Is the United Kingdom Police Service Receptive to Evidence-Based Policing? Unpublished MA thesis. University of Cambridge, UK.

Petersen, A. C. and Olsson, J. I. (2015). 'Calling Evidence-Based Practice into Question: Acknowledging Phronetic Knowledge in Social Work.' British Journal of Social Work, 45(5): 1581-1597.

Police Executive Research Forum. (2008). Violent Crime in America. Washington, DC: Police Executive Research Forum. 
Pope, N. D., Rollins, L., Chaumba, J. and Risler, E. (2011). 'Evidence-Based Practice Knowledge and Utilization Among Social Workers.' Journal of Evidence-Based Social Work, 8(4): 349-368.

Rohl, T. (1990). 'Moving to a Professional Status.' Police Journal, 71(6): 6-9.

Rojek, J., Alpert, G. and Smith, H. (2012). 'The Utilization of Research by the Police.’ Police Practice and Research, 13: 329-341.

Sherman, L. W. (1998). Evidence Based Policing. Washington, DC: Police Foundation.

Sherman, L. W. (2003). 'Misleading Evidence and Evidence-Led Policy: Making Social Science More Experimental.' Annals of the American Academy of Social and Political Science, 589: 6-19.

Sherman, L. W. (2013). 'The Rise of Evidence-Based Policing: Targeting, Testing, and Tracking.' Crime and Justice, 42(1): 377-451.

Sherman, L. W., Gottfriedson, D., MacKenzie, D., Eck, J., Reuter, P. and Bushway, S. (1997). Preventing Crime: What Works, What Doesn't, What's Promising. Report to the US Congress. Washington, DC: US Department of Justice.

Sherman, L. W., Gartin, P. R. and Buerger. M. E. (1989). 'Hot Spots of Predatory Crime: Routine Activities and the Criminology of Place.' Criminology, 27: 27-55.

Steinheider, B., Wuestewald, T., Boyatzis, R. E. and Kroutter, P. (2012). 'In Search of a Methodology of Collaboration: Understanding Research-Practitioner Philosophical Differences in Policing.' Police Practice and Research, 13(4): 357-374.

Telep, C. W. (2016). 'Police Officer Receptivity to Research and Evidence-Based Policing: Examining Variability Within and Across Agencies.' Crime \& Delinquency, iFirst DOI 10.1177/0011128716642253. 
Telep, C. W. and Lum, C. (2014). 'The Receptivity of Officers to Empirical Research and Evidence-Based Policing: An Examination of Survey Data From Three Agencies.’ Police Quarterly, 17(4): 359-385.

Telep, C. W. and Winegar, S. (2015). 'Police Executive Receptivity to Research: a Survey of Chiefs and Sheriffs in Oregon.' Policing: A Journal of Policy and Practice, iFirst DOI 10.1093/police/pav043.

Thacher, D. (2001). 'Policing is Not a Treatment: Alternatives to the Medical Model.' Journal of Research in Crime and Delinquency, 38(4): 387-415.

Tilley, N. (2009). 'Sherman vs Sherman: Realism vs Rhetoric.' Criminology \& Criminal Justice, 9(2): 135-144.

Tilley, N. (2015). 'There is Nothing so Practical as a Good Theory: Teacher-Learner Relationships in Applied Research for Policing.' In Cockbain, E. and Knutsson, J. (eds), Applied Police Research. Abingdon: Routledge.

Weisburd, D. and Lum, C. (2005). 'The Diffusion of Computerized Crime Mapping in Policing: Linking Research and Practice.' Police Practice and Research, 6: 419434.

Wood, J., Fleming, J. and Marks, M. (2008). 'Building the Capacity of Police Change Agents: the Nexus Policing Project.’ Policing \& Society, 18(1): 72-87.

\section{Notes}

\footnotetext{
${ }^{1}$ The WWCCR consists of an academic partnership consortium established in 2013 including University College London (UCL), the Institute of Education (IoE), the London School of Hygiene and Tropical Medicine, Birkbeck College, Cardiff, Dundee, Surrey and Southampton universities.
} 
${ }^{2}$ Police and Crime Commissioners (PCCs) in England and Wales are publicly elected officials with responsibility for police budgets and efficiencies. Commissioners replaced the now abolished police authorities. They were introduced by the government in 2010 with the first election of Police and Crime Commissioners (PCCs) in 41 of the 43 police forces taking place in November 2012, and the subsequent election more recently taking place in May 2016. PCCs are responsible for setting out in an annual police and crime plan the objectives they will address, allocating the funds needed to achieve them, and holding police forces accountable on behalf of the electorate. 